\title{
THE RATE OF ASCENT OF LIQUIDS THROUGH GRANULAR MEDIA.
}

\author{
By Felix E. Hackett, Ph.D., F.Inst.P., Lecturer in Physics, Royal \\ College of Science, Dưlin.
}

INTRODUCTION.

This note records the results of some experiments made in order to test the application of the equation for the capillary ascent of liquids in such media as sands or soils. This equation is derived readily by applying the theory of viscous flow to a vertical capillary tube. It was applied by Heber Green ${ }^{2}$ and Ampt to the ascent of water through soils but without satisfactory results.

This series of experiments was planned to eliminate some of the disturbing factors introduced by using soils. Sands of different grades were obtained by the use of sieves. Paraffin oil was substituted for water. Owing to the low surface tension of the oil, it wets the sand easily. There were therefore no anomalous effects such as occur with water owing to the difficulty with which it wets some sands. The ascent was observed in tubes of $2 \mathrm{~cm}$. diameter, closed at one end with wire gauze of 200 inch mesh. The sand was poured in and the tube gently tapped a few times as in experiments with soils.

The problem of capillary flow has lately been fully discussed by Washburn, ${ }^{2}$ Department of Ceramic Engineering, Illinois, so it is unnecessary to set forth details here. As the liquid ascends, air is forced out so that the viscosity of the air should be considered in exact equations. This effect is ignored here, also the question of slip, and of the angle of contact. We adopt the view that surface tension acts by supporting and removing part of the atmospheric pressure from the liquid beneath to an amount equal to the capillary rise $\mathrm{H}$. The theory of viscous flow gives, then, for a capillary tube of radius $a$ immersed vertically to a depth $d$ in a liquid of viscosity $\eta$, density $\rho$ and capillary height $\mathrm{H}$, the quantity of liquid $q$ ascending per unit time as,

$$
q=\frac{g \rho}{\eta} \cdot \frac{H+d-x}{x} \cdot \frac{\pi a^{4}}{8} . \quad . \quad . \quad .
$$

For a column of sand $q=\mathrm{AS} \frac{d x}{d t}$ where $\mathrm{A}$ is the cross section of the tube and $S$ is the pore space, we can write, then, for the velocity of ascent $v$,

$$
\frac{d x}{d t}=\frac{q}{\mathrm{AS}}=\frac{\mathrm{P}}{\mathrm{S}} \frac{\mathrm{H}+d-x}{x}=\mathrm{C} \frac{\mathrm{H}^{\prime}-x}{x} . \quad .
$$

I Green and Ampt., Fourn. Agric, Sci., IV, May, rgrr.

2 Washburn, Phys. Rev., March, I92. 


\section{ASCENT OF LIQUIDS THROUGH GRANULAR MEDIA 26I}

where $\mathrm{P}$ is the quantity termed by Green the permeability. It is convenient to replace $\frac{\mathrm{P}}{\mathrm{S}}$ by a single constant $\mathrm{C}$. Since the above equation is analogous to Ohm's law, where $\mathrm{H}^{\prime}-x$ corresponds to the E.M.F., $v$ to the electric current and $\frac{x}{\mathrm{C}}$ to the resistance, $\mathrm{C}$ may be considered as the specific conductivity or shortly the conductivity ${ }^{1}$ of the granular medium for any given liquid.

The relation of $\mathrm{C}$ to the constants of the liquid and the diameters of the sand particles can be derived from Slichter's theory of viscous flow through spherical grains. Green ${ }^{2}$ has given the general equation of flow on this theory in a convenient form for comparison with (2). We find-

$$
\mathrm{C}=\frac{g p}{\eta} \cdot \frac{\mathrm{I}}{96 k \mathrm{~S}} \sigma^{2}
$$

where $\sigma=$ diameter of sand grains,

$$
\begin{aligned}
\mathrm{S} & =\text { pore space }, \\
k & =f(\mathrm{~S}) .
\end{aligned}
$$

The values of $k$ for different values of $\mathrm{S}$ have been calculated by Slichter and are given by Green. ${ }^{2}$

\section{Experiments with Parafyin Oil.}

This series of experiments demonstrates that equation (2) can be applied to the initial stages of the ascent through a granular medium. It is wellknown, however, that this ascent goes on for a long time, and the quantity of liquid retained between the particles decreases with the height ascended. We can easily distinguish three conditions, wet, moist and damp. It is found that equation (2) only applies to the first stage in which the liquid rises rapidly and wets the sand. It may be called the wet stage of the ascent or briefly the rapid rise.

This is most easily illustrated by taking the integrated form of equation (2) -

$$
\log _{e} \frac{\mathrm{H}^{\prime}}{\mathrm{H}^{\prime}-x}-\frac{x}{\mathrm{H}^{\prime}}=t \frac{\mathrm{C}}{-\mathrm{H}^{\prime}} .
$$

and using it to calculate $t$ from the constants found by plotting the observed velocity $v$ against $x^{-1}$. According to (2) we should obtain a straight line, the equation of which can be written in the form-

\begin{tabular}{|c|c|c|c|c|c|c|c|c|}
\hline$x \mathrm{~cm}$ & . & 4.7 & $7 \cdot 85$ & $10 \cdot 85$ & I $3^{\circ} 9^{\circ}$ & $\mathbf{x}_{4} \cdot 6$ & $\mathrm{I}_{4} \cdot 98$ & $15 \cdot 3$ \\
\hline$t$ calc. min. & . & $I \cdot 3$ & $4 \cdot 30$ & II.5 & $3 I \cdot 6$ & $42 \cdot 0$ & $52 \cdot 0$ & 67.5 \\
\hline$t$ obs. min. & . & $I \cdot 0$ & 40 & $12 \cdot 0$ & $3 x \cdot 5$ & $42 \cdot 0$ & $52 \cdot 0$ & 57.5 \\
\hline
\end{tabular}

$$
v=\mathrm{CH}^{\prime}\left[\frac{\mathrm{I}}{x}-\frac{\mathrm{I}}{\mathrm{H}^{\prime}}\right] \text {. }
$$

TABLE I.

[Rapid rise of paraffin oil through sand of mean grade $0.0168 \mathrm{~cm}$.]

$$
\mathrm{CH}^{\prime}=10.60 \quad \mathrm{H}^{\prime}=\mathrm{r}_{5} .6 .
$$

The velocity graph against the inverse of the distance ascended is linear 
in the early part of the ascent as required by theory. The point at which this line cuts the axis is $\frac{\mathrm{I}}{\mathrm{H}^{\prime}}$. The graph for the ascent in Table $\mathrm{I}$. is given in Figure $\mathbf{I}$. It is seen that the line cuts the axis at $00_{4}$ indicating a height of $15^{\circ} 6$ at which the ascent should cease. As it approaches this point, the velocity, however, does not diminish according to the linear law and the graph turns sharply round to a curve asymptotic to the axis. Instead of the velocity dying down to zero according to (4), a slow creep persists. This effect is also shown in Table I. at $x_{5} 3$, for which the observed time is less than the calculated time.

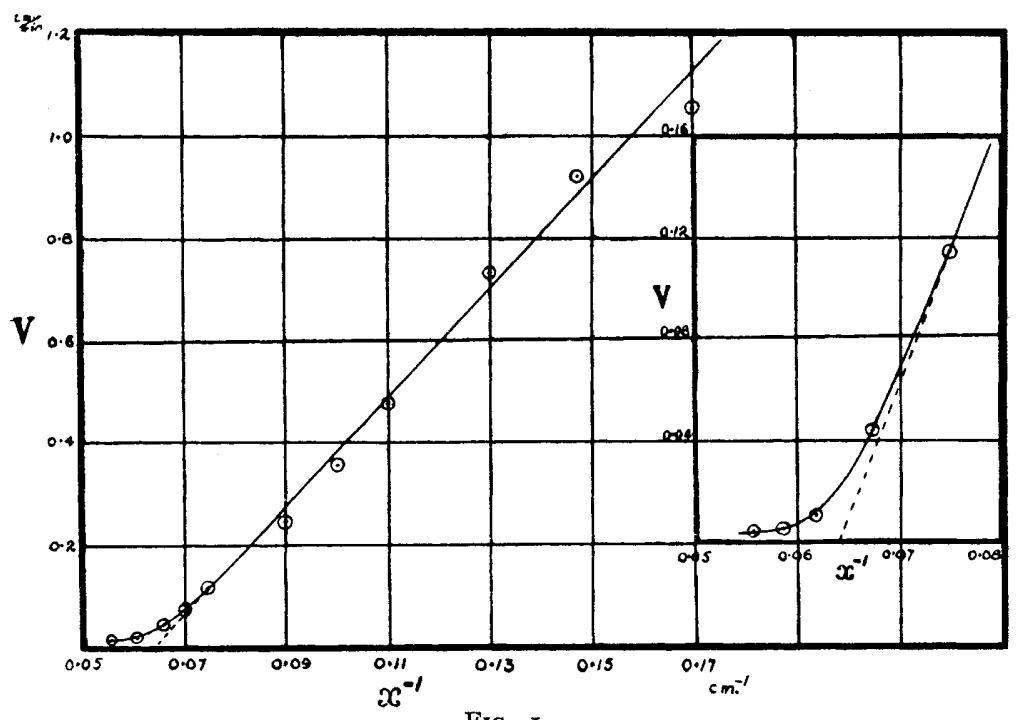

FIG. I.

Similar results were obtained for all the different grades of sand which were examined. The values of the constants $\mathrm{C}$ and $\mathrm{H}$ determined in the above manner for each are given in Table II. and discussed below.

TABLE II.

\begin{tabular}{|c|c|c|c|c|c|c|c|}
\hline Sand. & & $\begin{array}{c}\text { Apertures of } \\
\text { Grading Sieves } \mathrm{Cm} \text {. }\end{array}$ & $\begin{array}{c}\text { Mean Grade } \\
\sigma \mathrm{Cm} .\end{array}$ & $\underset{\mathrm{Cm}}{\mathrm{H}}$ & $\mathbf{H} \sigma$ & C Cm. Min. ${ }^{-1}$ & $\mathrm{CH}^{2}$. \\
\hline $\begin{array}{l}\text { River : } \\
\text { River : } \\
\text { Strand : } \\
\text { River : } \\
\text { River : } \\
\text { Pit : : } \\
\text { Moulding }\end{array}$ & $\dot{b}$ & $\begin{array}{c}.056-\cdot 028 \\
\cdot 028-\cdot 0205 \\
\cdot 0205-\cdot 0131 \\
.0205-\cdot 0131 \\
\cdot 0205-\cdot 0131 \\
\cdot 0131-0094 \\
\cdot 0094-.0076\end{array}$ & $\begin{array}{l}\cdot 042 \\
\cdot 0242 \\
\cdot 0168 \\
\\
\cdot 0168 \\
\cdot 0 r 68 \\
\cdot 0108 \\
\cdot 0085\end{array}$ & $\begin{array}{l}6 \cdot 9 \\
11 \cdot 1 \\
9 \cdot 85 \\
13 \cdot 6 \\
15 \cdot 0 \\
15 \cdot 1 \\
22 \cdot 4 \\
42 \cdot 0\end{array}$ & $\begin{array}{l}\cdot 290 \\
\cdot 268 \\
\cdot 165 \\
\cdot 228 \\
\cdot 252 \\
\cdot 253 \\
\cdot 242 \\
\cdot 356\end{array}$ & $\begin{array}{l}2.44 \\
.894 \\
\mathrm{r} \cdot 57 \\
.56 \\
.616 \\
.68 \\
.364 \\
.0084\end{array}$ & $\begin{array}{l}\text { II5 } \\
\text { II6 } \\
\text { I52 } \\
\text { I02 } \\
\text { I37 } \\
\text { I55 } \\
\text { I80 } \\
\text { I48 }\end{array}$ \\
\hline \multicolumn{5}{|c|}{ Mean } & $\cdot 257$ & & $13^{8}$ \\
\hline
\end{tabular}

The third sample in this table shows an effect which might have been anticipated, viz. two different rates of ascent. This would take place if the 
packing is not uniform or if we had a mixture of grains of markedly different grades. An initial rapid ascent through wider interstices being overtaken by an initially slower ascent through narrower spaces. We get, then, for the velocity graph two straight lines from which we can calculate the constants $\mathrm{C}$ and $\mathrm{H}$. This set of observations has been included in this table, and treated as two independent observations on the mean grade of sand used. The mean values obtained are slightly altered, but the general conclusions are unaffected.

In this table the mean grade is taken as the mean of the apertures in the sieves used in sifting out the sand. Under $\mathrm{H}$ is given the capillary height of the rapid ascent deduced from the velocity graph and corrected by the depth of immersion of the tube. For capillary ascent $\mathrm{H} \times$ radius is constant so here $\mathrm{H} \sigma$ should be constant. Considering the material used, the relation is fairly well obeyed.

We may inquire into the possible values of $\mathrm{H} \sigma$ with spherical grains arranged in cubical order sometimes called loose packing or in the pyramidal order of close packing. In close packing the contact of three spheres forms a curvilinear triangle. We may take the surface tension around the perimeter of this triangle as holding up a column of liquid of height $\mathrm{H}$ occupying the area. The result of this calculation is given below. We can make a similar calculation for cubical packing. Keen ${ }^{1}$ applies the same mode of calculation to a column having as section an equilateral triangle. He takes Slichter's result that the pores in the sand can be regarded as of triangular section where the side of triangle $=\mathrm{I}^{\cdot} 4 \sigma$ and finds $\mathrm{H} \sigma=\mathrm{x} 9.8 \frac{\mathrm{T}}{g_{\rho}}$. Taking $\mathrm{T}_{20}=25.7, \rho_{20}=0.799$ for the paraffin oil used, the mean value of $\mathrm{H} \sigma$ in Table II. gives $\mathrm{H}_{\sigma}=7.84 \frac{\mathrm{T}}{g \rho}$. We find, then-

$$
\begin{aligned}
& \mathrm{H} d=4 \frac{\mathrm{T}}{g \rho} \text { capillary tube of diameter } d . \\
& \mathrm{H} \sigma=7 \cdot 84 \frac{\mathrm{T}}{g \rho} \text { sand experiments. } \\
& \mathrm{H} \sigma=\mathrm{I} 4 \cdot 6 \frac{\mathrm{T}}{g \rho} \text { cubical packing. } \\
& \mathrm{H} \sigma=\mathrm{r} 9 \cdot 8 \frac{\mathrm{T}}{g \rho} \text { Keen's estimate. } \\
& \mathrm{H} \sigma=39 \cdot \circ \frac{\mathrm{T}}{g \rho} \text { close packing. }
\end{aligned}
$$

The mathematical calculation is of course an upper limit. It assumes that at the surface the grains are all immersed to their diametral plane whereas the immersion may vary from complete immersion to mere contact. This would make a considerable reduction in the numerical constant which would account for the low value found in these sand experiments.

Since $\mathrm{C}$ from equation (3) varies as $\sigma^{2}$ we expect to find $\mathrm{CH}^{2}$ constant. The relation is tested in the last column. The variations in the values are not excessive. From the mean values of $\mathrm{CH}^{2}$ and $\mathrm{H} \sigma$ we can derive an expression for $\mathrm{C}$ in the form of (3), $\rho_{20}=0.799$ and $\eta_{20}=.0146$ for the paraffin oil used. We find 
or in $\mathrm{cm} . \mathrm{sec}^{-1}$ units.

$$
\mathrm{C}=\frac{\mathrm{CH}^{2}}{(\mathrm{H} \sigma)^{2}} \sigma^{2}=2089 \sigma^{2}=\frac{g \rho}{\eta \eta} \cdot \frac{\sigma^{2}}{25 \cdot 7}
$$

$$
\mathrm{C}=\frac{g \rho}{\eta} \cdot \frac{\sigma^{2}}{\mathrm{I}_{542}}
$$

The porosity of the sand in these tubes was not determined in situ. The porosity of a sample settled by tapping was found to be $4 \mathrm{I}$ per cent. In Green's experiments 39 per cent. was the usual value. We may calculate the value of $\mathrm{C}$ taking $\mathrm{S}=40$ per cent. and $k=20.3$ in equation (3). We find

$$
\mathrm{C}=\frac{g \rho}{\eta} \cdot \frac{\sigma^{2}}{780}
$$

The conductivity is therefore about half that given by Slichter's formula which, as Green has shown, was found in agreement with percolation experiments on sand. In such experiments the advance of the liquid is uniform, but in the capillary rise, the advance of the liquid may take place in some channels rather than others. The liquid rising in these will fill the spaces in the sand surrounding them at any level, and so reduce the rate of advance and give a smaller value for the conductivity.

\section{Initial Rise with Fleuss Oil.}

Experiments with Fleuss oil were more difficult owing to the slow rate of ascent which spread the period of the initial rise over twenty-four hours. A full series was not completed, but enough data were obtained to confirm

\begin{tabular}{|c|c|c|c|c|c|c|}
\hline Sand. & $\begin{array}{l}\text { Apertures of } \\
\text { Grading Sieves } \mathrm{Cm} .\end{array}$ & $\begin{array}{l}\text { Mean Grade } \\
\sigma \mathrm{Cm} \text {. }\end{array}$ & $\underset{\mathrm{Cm}}{\mathrm{H}}$ & $\begin{array}{l}\mathrm{H} \sigma \\
\mathrm{Cm}\end{array}$ & C Cm. Min. ${ }^{-1}$ & $\mathrm{CH}^{2}$. \\
\hline $\begin{array}{l}\text { River . } \\
\text { Strand } \\
\text { River. } \\
\text { Moulding }\end{array}$ & $\begin{array}{c}\cdot 056-\cdot 028 \\
\cdot 028-\cdot 0205 \\
\cdot 0205-.0131 \\
\cdot 0094-.0076\end{array}$ & $\begin{array}{l}\cdot 0242 \\
\cdot 0168 \\
\cdot 0085\end{array}$ & $\begin{array}{l}4 \\
6 \cdot 35 \\
(9 \cdot 65) \\
13 \cdot 0 \\
13 \cdot 6 \\
38 \cdot 2\end{array}$ & $\begin{array}{l}\cdot 168 \\
\cdot 276 \\
(\cdot 405) \\
\cdot 315 \\
\cdot 23 \\
\cdot 326\end{array}$ & $\begin{array}{l}\cdot 318 \\
\cdot \text { ro2 } \\
(\cdot 0103) \\
\cdot 037 \\
\cdot 0405 \\
\cdot 00407\end{array}$ & $\begin{array}{l}5 \cdot 1 \\
4 \cdot 0 \\
(0 \cdot 94) \\
6 \cdot 25 \\
7 \cdot 5 \\
6 \cdot 86\end{array}$ \\
\hline & \multicolumn{3}{|c|}{ Mean } & $\cdot 263$ & & $5 \cdot 94$ \\
\hline
\end{tabular}
the conclusions stated above.

TABLE III.

The first example of this series also shows three different rates of ascent, which may be accounted for by the same reasons as given under Table II. It seems well to omit the third member of this set as not comparable with the rest. The observations for the strand sand seem to belong more to the next grade. For purposes of comparison the same method of averaging is again adopted. Using the values $T_{20}=28.6$ dynes $/ \mathrm{cm} . \quad \rho_{20}=0.872$ and $\eta_{20}=0.242$ c.g.s. units, we find, calculating as before,

$$
\left.\begin{array}{rl}
\mathrm{H} \sigma & =7 \cdot 86 \frac{\mathrm{T}}{\rho g} \\
\mathrm{C} & =\frac{\rho g}{\eta} \cdot \frac{\sigma^{2}}{2470} \mathrm{~cm} . \mathrm{sec}^{-1}
\end{array}\right\} \text { Fleuss oil. }
$$


in comparison with

$$
\left.\begin{array}{rl}
\mathrm{H} \sigma & =7 \cdot 84 \frac{\mathrm{T}}{\rho g} \\
\mathrm{C} & =\frac{\rho g}{\eta} \cdot \frac{\sigma^{2}}{\mathrm{I} 54^{2}} \mathrm{~cm} . \mathrm{sec}^{-1}
\end{array}\right\} \text { Paraffin oil. }
$$

Since the values of $\frac{\mathrm{T}}{\rho}$ for paraffin oil and Fleuss oil may be taken as $32 \cdot 2$ and $32 \cdot 8$ respectively, the capillary heights for the same grade of sand for these two liquids should be equal. This is not shown in the tables, but the mean values agree in the numerical constant they give in the general formula - probably an accidental result. As regards conductivity, the ratio of the values of $\frac{\eta}{\rho}$ for the two oils is $15^{\circ 2}$. A mean value for $\mathrm{CH}^{2}$ of 9.08 would be expected instead of $5 \% 95$. Slight differences in packing would account for some, at any rate, of these divergencies from theoretical anticipations.

The essential conclusions remain unaltered in spite of these discrepancies in the results. We may therefore state that the initial rate of ascent of liquids in sand agrees very closely with the theory of capillary flow in tubelike spaces between the particles. As a first approximation we may take

$$
\mathrm{H} \sigma=8 \frac{\mathrm{T}}{g \rho}
$$

for the capillary rise in sand of average diameter $\sigma$, and write for the average conductivity the mean of the values given above :-

$$
\mathrm{C}=\frac{\rho g}{\eta} \cdot \frac{\sigma^{2}}{\mathrm{I} 900} \text {. }
$$

\section{SLOW RisE.}

The slow rise which makes its appearance after the rapid rise has been completed is also in some respects similar to an ascent in a cylindrical tube. We assume tentatively that it is probably due to the irregularities in the sand grains which form passages of smaller area. The velocity graph against the inverse of the height is no longer linear. It becomes linear over a short section, however, if the ascent is reckoned from the height attained in the previous rapid rise. This is what would occur if the ascent took place in a fine capillary pore, giving a capillary height $h_{s}$, branching off from some of the main pores at their capillary height $\mathrm{H}$. Using dashed letters to indicate heights measured from the bottom of the tube instead of the liquid level, the velocity equation becomes-

$$
\mathrm{V}=\mathrm{C} \frac{\left(h_{s}^{\prime}-\mathrm{H}^{\prime}\right)-\left(x-\mathrm{H}^{\prime}\right)}{x-\mathrm{H}^{\prime}}=\mathrm{C}\left(h_{s}^{\prime}-\mathrm{H}^{\prime}\right)\left[\frac{\mathrm{I}}{x-\mathrm{H}^{\prime}}-\frac{\mathrm{I}}{h_{s}^{\prime}-\mathrm{H}^{\prime}}\right] .
$$

Having determined $\mathrm{C}$ and $h_{s}{ }^{\prime}-\mathrm{H}^{\prime}$ from the linear portion of the graph we can use equation (4) to calculate the time substituting $x-\mathrm{H}^{\prime}$ for $x$, $h_{s}^{\prime}-\mathrm{H}^{\prime}$ for $\mathrm{H}^{\prime}$. To this value of the time has to be added the time $\mathrm{T}$ taken to reach $\mathrm{H}$ since the ascent only begins from this point. The results for the same tube as in Table II. are shown in Tables IV. and V. 
TABLE IV.

[First slow rise of paraffin oil in sand of grade $0 \mathrm{I} 68 \mathrm{~cm}$.]

\begin{tabular}{|c|c|c|c|c|c|c|c|c|c|}
\hline $\begin{array}{l}x \text { in cm. } \\
t \text { calc. in hr. } \\
t \text { obs. in hr. }\end{array}$ & $\cdot$ & $\begin{array}{l}16 \cdot 5 \\
2 \cdot 36 \\
2 \cdot 50\end{array}$ & $\begin{array}{r}17 \cdot 4 \\
4 * 9 \\
5^{\circ} \mathrm{O}\end{array}$ & $\begin{array}{l}\text { r8.3 } \\
9 \cdot 50 \\
9 \cdot 65\end{array}$ & $\begin{array}{l}19.2 \\
17^{\circ}, \\
16.6\end{array}$ & $\begin{array}{l}2 I \cdot I \\
45 \cdot 2 \\
46 \cdot 2\end{array}$ & $\begin{array}{l}22 \cdot 0 \\
7 I^{\circ} 0 \\
7 I^{\circ} \cdot 5\end{array}$ & $\begin{array}{r}22 \cdot 9 \\
113 \cdot 0 \\
106 \cdot 8\end{array}$ & $\begin{array}{r}23 \cdot 8 \\
197 \\
167\end{array}$ \\
\hline
\end{tabular}

$$
h_{s}^{\prime}=24.7 \quad \mathrm{H}^{\prime}=\mathrm{I}_{5} \cdot 6 \quad \mathrm{C}=\mathrm{I} \cdot \mathrm{I} \times \mathrm{I}^{-3} \quad \mathrm{~T}=100 \mathrm{~min} .
$$

The agreement is as satisfactory as can be expected. The correction of the time zero ( $\mathrm{T}$ ) approximates to the time required by the rapid rise to reach $15^{\circ} 6$. If the rise is due to the pull of a capillary height $h_{s}$, the conductivity is of quite a different order to that of the rapid rise in sand of finer grain having the same capillary height since $C h_{s}^{2}=0.645$.

The slow rise continues beyond this point and a second stage makes its appearance. The velocity graph plotted in the same way $v$ against $\left(x-15^{\circ}\right)^{-1}$ can again be represented over a stretch by a straight line. As before the constants of this straight line can be used to calculate the time as shown in Table V.

TABLE V.

[Second slow rise of paraffin oil in sand of grade $\cdot 0 \mathrm{r} 68 \mathrm{~cm}$.

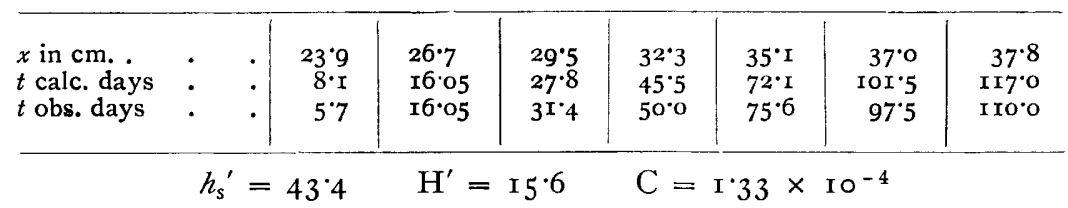

It is scarcely necessary to point out the many sources of error in these observations which extend over many months during which the temperature ranged from $10^{\circ} \mathrm{C}$. to $20^{\circ} \mathrm{C}$. In addition we have the variations due to packing and changes of packing produced by the capillary pull causing breaks in the column of sand. The calculated values in Table V., therefore, do not show as good agreement as previous tables, but still they follow the rate of ascent sufficiently closely for a period of three months.

The results of this investigation are collected below in the few cases in which it was carried out. In all cases, the constants given here were tested by agreement between the calculated and observed times to the same degree of approximation as shown in Tables IV. and V. In Table VI., $h_{s}$ of course represents the height at which each type of slow rise ceases, measured from the liquid level, while $\mathrm{H}$ is the capillary height of the rapid rise.

TABLE VI.

[Summary of results on slowe rise.]

\begin{tabular}{|c|c|c|c|c|c|c|c|c|}
\hline \multicolumn{3}{|c|}{ Sand. } & Liquid. & Grade $\mathrm{Cm}_{\mathrm{m}}$. & H. & $h_{s}$ & $\mathrm{C} \times 104$. & $\mathrm{C} h_{s}{ }^{2}$. \\
\hline River & . & . & Paraffin oil & -or68 & $I_{5} \cdot \mathrm{I}$ & $24 \cdot 2$ & $x I 0$ & $\cdot 045$ \\
\hline Strand & & - & , & •ог68 & $13 \cdot 6$ & $\begin{array}{l}42 \cdot 9 \\
23 \cdot 7 \\
4 I \cdot I\end{array}$ & $\begin{array}{l}r \cdot 33 \\
4 \cdot 72 \\
0 \cdot 864\end{array}$ & $\begin{array}{l}\cdot 244 \\
\cdot 266 \\
\cdot 146\end{array}$ \\
\hline River & & . & Fleuss oil & 'or 68 & $13 \cdot 6$ & $\begin{array}{l}18 \cdot 75 \\
21 \cdot 65\end{array}$ & $\begin{array}{l}4 \cdot I \\
I \cdot I 9\end{array}$ & $\begin{array}{l}\cdot r_{44} \\
\cdot 056\end{array}$ \\
\hline Strand & . & . & $\cdot \quad$, & 'or68 & $13^{\circ} \mathrm{O}$ & 16.0 & $1 \cdot 3$ & $\cdot 033$ \\
\hline
\end{tabular}


The product $\mathrm{C}_{s}{ }^{2}$ is taken here again by analogy to test the theory that this slow rise is through minute channels. The observations in Table VI. extended over three months. For comparison the observations were continued over a year. In six months the heights $h_{s}$, deduced from observations over three months, were attained as shown in Table VII.

TABLE VII.

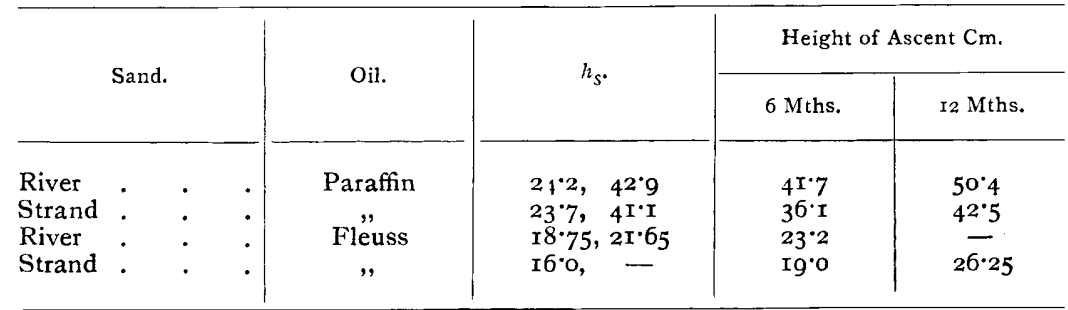

There does not seem to be any reason to consider this very slow creep which can scarcely be said to moisten the sand as a different physical process from the slow rise. It merely confirms Table VI., showing the superior ascending qualities of paraffin oil. The theory assumed that the ascent took place through fine capillaries. The results of the analysis do not confirm this view for the following reasons: ( $\mathrm{I}$ ) the values of $h_{s}$ for same grade of sand should not differ as they do since $\frac{T}{\rho}$ has nearly the same value for both oils; (2) the constant $\mathrm{C}$ depends on the viscosity and should vary inversely as $\frac{\eta}{\rho}$, i.e. as $\mathrm{I}$ to $\mathrm{I} 5$; the average ratio is more nearly $\mathrm{I}$ to 2 : (3) the value of $\mathrm{C} h^{2}$ should not be very different from the values in Tables II. and III., whereas it is 400 times smaller in one case and 70 times smaller in the other. There is therefore no sound physical basis for the equation proposed. It serves a useful purpose, however, in referring the results of observations to two series of constants which express them concisely.

One explanation of these results is that we have fine capillaries blocked by small dust particles. We might also take the view that we are not dealing with a true capillary ascent but with an ascent due to the diffusion of vapour in which surface tension acts by promoting condensation in the spaces between the particles.

The greater distances ascended by paraffin would then be due to its greater vapour tension. Experiments with truly spherical grains are required to decide this question.

\section{Summary.}

The ascent of liquids in sands which takes place in two to twenty-four hours, according to the viscosity of the liquid, satisfies the laws of capillary flow for the tube-like spaces between the grains.

The ascent may continue for over a year, and the final heights attained may be two to three times the height reached in the first stage. This second stage satisfies an equation similar to that for capillary flow, but the constants deduced are not in agreement with the theory of capillary flow. 